\title{
First evidence on phloem transport of nanoscale calcium oxide in groundnut using solution culture technique
}

\author{
Manchala Deepa • Palagiri Sudhakar · Kandula Venkata Nagamadhuri • \\ Kota Balakrishna Reddy • Thimmavajjula Giridhara Krishna • \\ Tollamadugu Naga Venkata Krishna Vara Prasad
}

Received: 23 July 2014/ Accepted: 11 August 2014/Published online: 22 August 2014

(C) The Author(s) 2014. This article is published with open access at Springerlink.com

\begin{abstract}
Nanoscale materials, whose size typically falls below $100 \mathrm{~nm}$, exhibit novel chemical, physical and biological properties which are different from their bulk counterparts. In the present investigation, we demonstrated that nanoscale calcium oxide particles $(\mathrm{n}-\mathrm{CaO})$ could transport through phloem tissue of groundnut unlike the corresponding bulk materials. $\mathrm{n}-\mathrm{CaO}$ particles are prepared using sol-gel method. The size of the as prepared $n-C a O$ measured $(69.9 \mathrm{~nm})$ using transmission electron microscopic technique (TEM). Results of the hydroponics experiment using solution culture technique revealed that foliar application of $\mathrm{n}-\mathrm{CaO}$ at different concentrations (10, $50,100,500,1,000 \mathrm{ppm}$ ) on groundnut plants confirmed the entry of calcium into leaves and stems through phloem compared to bulk source of calcium sprayed $(\mathrm{CaO}$ and $\mathrm{CaNO}_{3}$ ). After spraying of $\mathrm{n}-\mathrm{CaO}$, calcium content in roots, shoots and leaves significantly increased. Based on visual scoring of calcium deficiency correction and calcium content in plant parts, we may establish the fact that nanoscale calcium oxide particles (size $69.9 \mathrm{~nm}$ ) could move through phloem tissue in groundnut. This is the first report on phloem transport of nanoscale calcium oxide
\end{abstract}

Electronic supplementary material The online version of this article (doi:10.1007/s13204-014-0348-8) contains supplementary material, which is available to authorized users.

M. Deepa $\cdot$ K. Balakrishna Reddy

Department of Crop Physiology, S.V. Agricultural College,

Acharya N G Ranga Agricultural University, Tirupati, India

P. Sudhakar · K. V. Nagamadhuri · T. Giridhara Krishna ·

T. N. V. K. V. Prasad ( $\square)$

Institute of Frontier Technology, Regional Agricultural Research

Station, Acharya N G Ranga Agricultural University, Tirupati, India

e-mail: tnvkvprasad@gmail.com particles in plants and this result points to the use of nanoscale calcium oxide particles as calcium source to the plants through foliar application, agricultural crops in particular, as bulk calcium application through foliar nutrition is restricted due to its non-mobility in phloem.

Keywords Nanotechnology $\cdot$ Nanomaterials $\cdot$ Calcium oxide $\cdot$ Phloem $\cdot$ Mobility $\cdot$ Groundnut

\section{Introduction}

Nanoparticles are atomic or molecular aggregates posing modified physical-chemical properties compared to the bulk materials and having less than $100 \mathrm{~nm}$ measured size in at least one dimension ( $\mathrm{Nel}$ et al. 2006). In the recent decade, nanomaterials have received tremendous attention for their positive impact in improving many sectors including consumer products, pharmaceutics, cosmetics, energy, medicine, etc. (Roco 2003). But limited reports are available on the positive effects of nanomaterials on plants (Prasad et al. 2012), agricultural plants in particular. Pronounced effect on increase in root and shoot length as well as accumulation of biomass in green gram was recorded for nanomaterial-treated plant as compared to control. Maximum effect was found at $50 \mathrm{ppm} \mathrm{ZnFeCu}$-oxide followed by $50 \mathrm{ppm} \mathrm{FeO}$ and least for $20 \mathrm{ppm} \mathrm{ZnO}$ (Dhoke et al. 2013). Studies on the toxicity of nanomaterials are still emerging and basically evidence several negative effects on growth and development of plants (Monica et al. 2011). Several reports confirmed the potential toxic effects of nanomaterials on higher plants ( $\mathrm{Lu}$ et al. 2002; Lin and Xing 2007; Lee et al. 2008; Ma et al. 2010).

The concept that nanomaterials could be of useful in agricultural systems is a relatively new one and under 
development now. Nanotechnology in agriculture would be of interest of developing countries, promising to reduce hunger, malnutrition and child mortality. The application of nanomaterials in agriculture aims to reduce nutrient losses in fertilization and to increase yields through nutrient management (Srilatha 2011: Sharon et al. 2010: Garica et al. 2010; Rashidi and Khosravi-Darani 2011). Several factors that influence the efficiency of fertilizers could be addressed using nanomaterials. Nanomaterials applications in agriculture and their potential advantages are evident through reports in the literature (Srilatha 2011; Ghormade et al. 2011; Garica et al. 2010). For example, nanomaterials with high surface area and with appropriate sorption properties may minimize losses by reducing runoff and with slow releasing kinetics. Specially designed nanoparticles could enhance the uptake and translocation of nutrients in the plants.

Use of nanomaterials in agriculture-specifically in plant nutrition-may pose unforeseen risks because these applications have the potential to release nanomaterials into the environment. Human and environmental exposure to nanomaterial residues in crops and soil increases accordingly due to the bioaccumulation of nanomaterials in the environment and food chain. As agriculture is aiming to sustainable management of natural resources, the application of nanomaterials must be critically evaluated towards safety of their usage in agriculture. Most importantly, their application methods must be standardized for low input fluxes and to minimize the environmental hazards thereby.

Calcium is an essential plant nutrient that plays structural role in the cell wall and membranes and regulates plant growth and development (Helper 2005). It acts as a critical part of the cell wall and forms strong structural rigidity by forming cross-links within the pectin polysaccharide matrix. Along with the plant growth, the structural integrity of stems that hold flowers and fruit, as well as the quality of the fruit produced, are strongly coupled to calcium availability. Further, calcium enhances the disease resistance in plants against bacterial and viral diseases (Usten et al. 2006).

The most critical element in the production of groundnut with sound mature kernels is calcium (Meena and Malarkodi 2007). Calcium is an immobile element in phloem. Calcium moves upward (xylem) in the peanut plant, but does not move downward (phloem). Thus, calcium does not move through the peg to the pod and developing kernel. (Webb and Hansen 1989). Skelton and Shear (1971) stated that calcium is poorly translocated via the phloem of the gynophores and must be absorbed by the developing pod. However, groundnut crop is mostly cultivated in rain-fed conditions, where moisture cannot be assured at the time of gypsum application, continued to suffer due to calcium deficiency. Hence calcium application through foliar nutrition is research priority. Any element at nanoscale amenable for change in property specially increased surface area which enhances biological reactivity in plant cells. Calcium at nanoscale is presumed to acquire enhanced properties in a biological system including its mobility (Prasad et al. 2012).

The aim of this study was to test whether nanoscale calcium oxide particles can transport through phloem where the mobility of the bulk form is restricted and further to reveal that foliar application of nanoscale oxide particles could be used as one of the best calcium nutrient sources for the agricultural crops. To the best of our knowledge, this is the first report on evidenced phloem transport of nanoscale calcium oxide in groundnut.

\section{Materials and methods}

Experimental details (hydroponics)

The experiment was conducted in solution culture in a glass house at the Department of Crop Physiology, S.V.Agricultural College, Acharya N G Ranga Agricultural University, Tirupati. The groundnut seedlings (var. Narayani) were raised on acid-free quartz sand which was transferred to plastic troughs containing Hoagland solution on the eighth day after sowing. Aeration of the seedlings was regularly maintained by bubbling air into the nutrient solution by using an aquarium pump and without any damage to the root system. The experiment consists of eight treatments, viz., (1) Control (+Ca), (2) Bulk $\mathrm{CaNO}_{3}$ $0.1 \%$, (3) Bulk $\mathrm{CaO} 0.1 \%$, (4) Nano-CaO 10 ppm, (5) Nano-CaO 50 ppm, (6) Nano-CaO 100 ppm, (7) Nano$\mathrm{CaO} 500$ ppm, (8) Nano-CaO 1,000 ppm.

\section{Sowing}

The quartz sand was thoroughly washed with normal tap water followed by overnight soaking of the sand in $5 \%$ $\mathrm{HCl}$. Then sand was washed with distilled water (DW) to make the sand acid free. Later sand was washed with double distilled water (DDW) for several times again. Groundnut Narayani seeds were sown in trays containing acid-free sand and seedlings were irrigated with double distilled water up to 7 days.

Preparation of solution culture

The culture solution was prepared in double distilled water following the dilutions of the stock solution and was stored in 1-L plastic beakers. Aeration to the root was provided by 
bubbling air into the solution using an aquarium air pump. The solutions were changed every week.

Cement planks with a middle hole for plant and a side hole for the aeration tube was used as the lid for the beaker. The seedlings were carefully introduced through the hole and fixed with a pad of cotton so as the roots were completely immersed in the solution. The seedlings received half strength nutrient solution for the first week and later full strength solution. The solution level in the beakers was maintained by adding distilled water everyday. The plants were raised for 25 days and sampled. All the containers were randomized to reduce positional effects with three replications. The experiment was conducted in a glass house having a mean day and night temperature of 30 and $25{ }^{\circ} \mathrm{C}$, respectively.
Nutrient composition

The composition of nutrient solution is given in Table 1. The nutrient solution used is a modified form of Hoagland formula (Johnson et al. 1957). All the reagents were of analytical grade and were used without further purification. 15 days after transferring to Hoagland solution, calcium deficiency symptoms developed. The treatments were imposed after noticing the deficiency symptoms. The composition of nutrient solution is given in Table 1. The nutrient solution used is a modified form of Hoagland formula. The developmental sequence of visual deficiency symptoms were carefully observed and documented. Calcium content was quantified in plant parts treatment-wise after terminating the experiment.

Table 1 Composition of Hoagland solution for solution culture technique

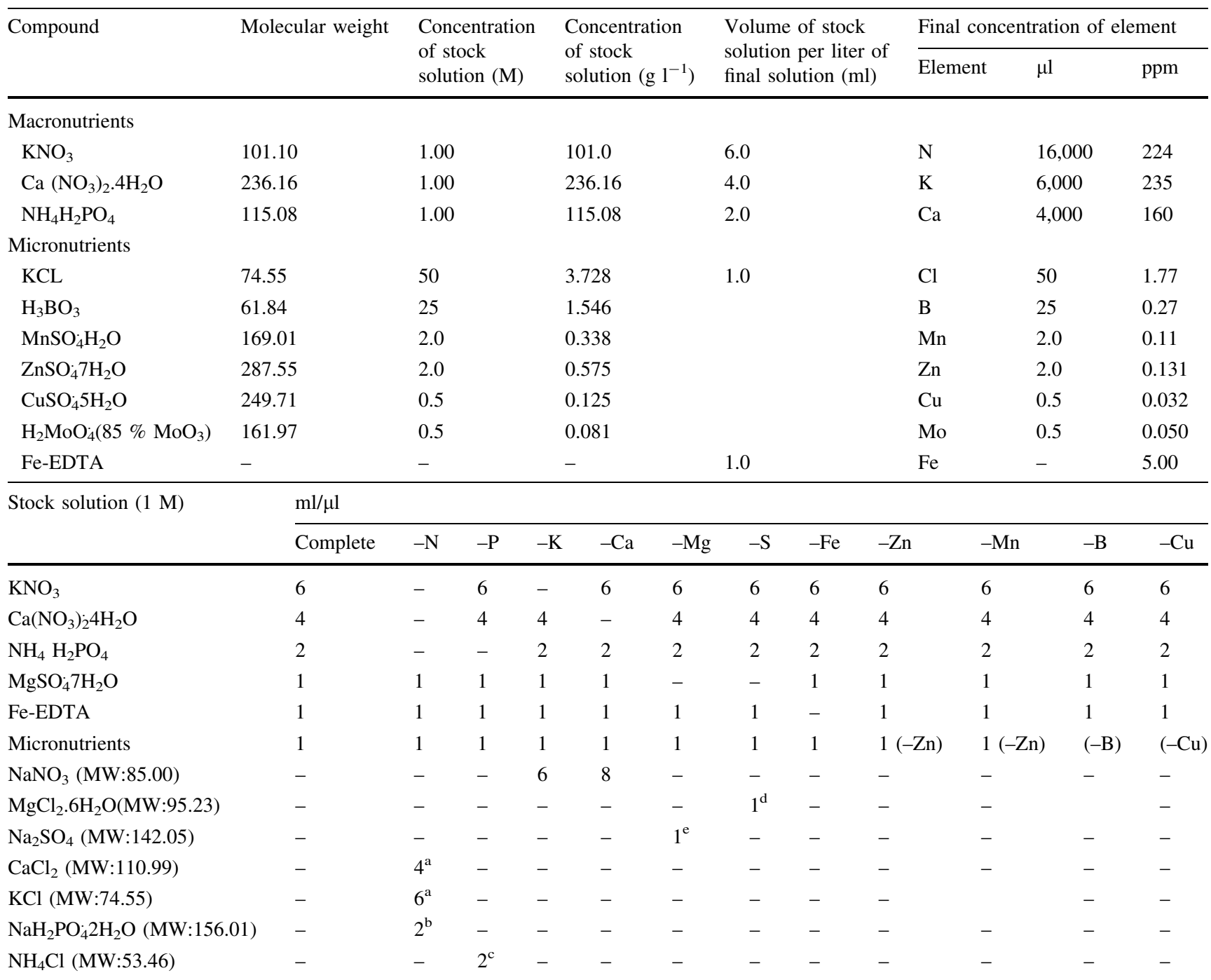

Preparation of Fe-EDTA: dissolved 26,1 g EDTA in $286 \mathrm{ml}$ of $1 \mathrm{~N} \mathrm{KOH}$. Mixed this with $24.9 \mathrm{~g} \mathrm{FeSO}_{4} 7 \mathrm{H}_{2} \mathrm{O}$ and diluted to $1 \mathrm{~L}$ before aeration. $1 \mathrm{ml}$ of this solution provided $5 \mathrm{ppm}$ in $1 \mathrm{~L}$

a $355 \mathrm{ppm}$ of $\mathrm{Cl},{ }^{\mathrm{b}} 45 \mathrm{ppm}$ of $\mathrm{Na},{ }^{\mathrm{c}} 71 \mathrm{ppm}$ of $\mathrm{Cl},{ }^{\mathrm{d}} 35 \mathrm{ppm}$ of $\mathrm{Cl},{ }^{\mathrm{e}} 23 \mathrm{ppm}$ of $\mathrm{Na}$ 


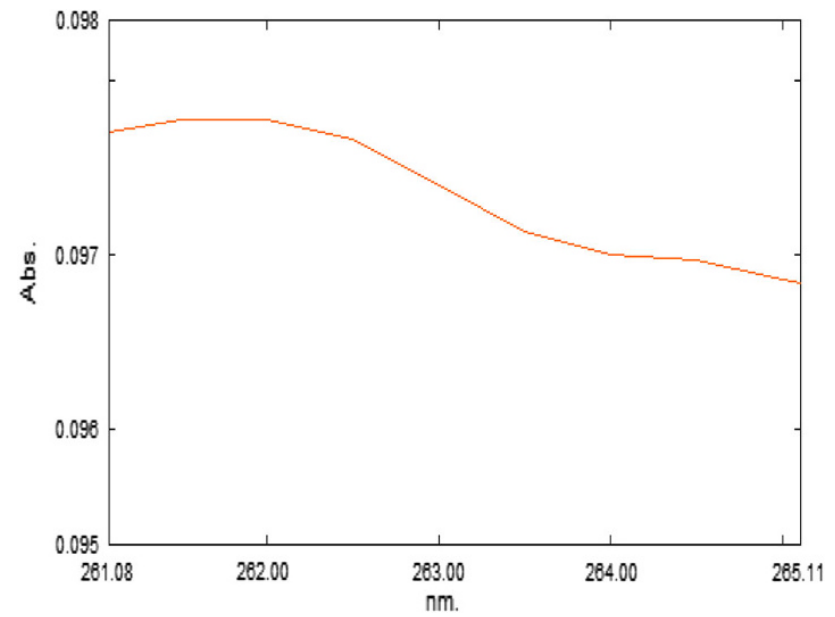

Fig. 1 UV-Vis micrograph showing typical absorbance (262 nm) of chemically synthesized $n-\mathrm{CaO}$

Preparation of nanoscale calcium oxide (n-CaO) particles

Nanoscale calcium oxide particles $(\mathrm{n}-\mathrm{CaO})$ were prepared using sol-gel method. $1 \%$ of calcium nitrate (Tetrahydrate purified LR, Sd-fine chemicals Ltd, Mumbai, India) was mixed with $0.05 \%$ of sodium citrate tribasic dehydrate (extra pure AR, Sd-fine chemicals Ltd, Mumbai, India) and stirred at $60{ }^{\circ} \mathrm{C}$ for $3 \mathrm{~h}$. Then the solution was filtered using filter paper (Whatman no. 1) and dried at $100{ }^{\circ} \mathrm{C}$ for $6 \mathrm{~h}$. The collected powder was used for further characterization and experimental studies.

$\mathrm{UV}-\mathrm{Vis}$ spectroscopic analysis

Solution of $\mathrm{n}-\mathrm{CaO}$ was prepared by mixing $0.1 \mathrm{gm}$ of $\mathrm{n}-\mathrm{CaO}$ powder in $100 \mathrm{ml}$ of water and stirred for $10 \mathrm{~min}$. Then the solution was taken into $3 \mathrm{ml}$ cuvette (Quartz) and scanned between 200 and $1,100 \mathrm{~nm}$ using the UV-Vis spectrophotometer (Shimadzu, UV-2450) and recorded the characteristic absorbance of the $\mathrm{n}-\mathrm{CaO}$.

\section{Transmission electron microscopy (TEM)}

Transmission electron microscopy (TEM) samples were prepared by pipetting the drops of calcium hydrosol on 200-mesh carbon-coated copper grids and allowing sample to dry in air. TEM micrographs were obtained using a Jeol 2010F HRTEM operating at $200 \mathrm{keV}$.

Particle size and zeta potential measurements

The hydrodynamic radius of the hydrosols is measured using the dynamic light scattering (DLS) technique wherein the scattering angle of laser light from the hydrosol is recorded

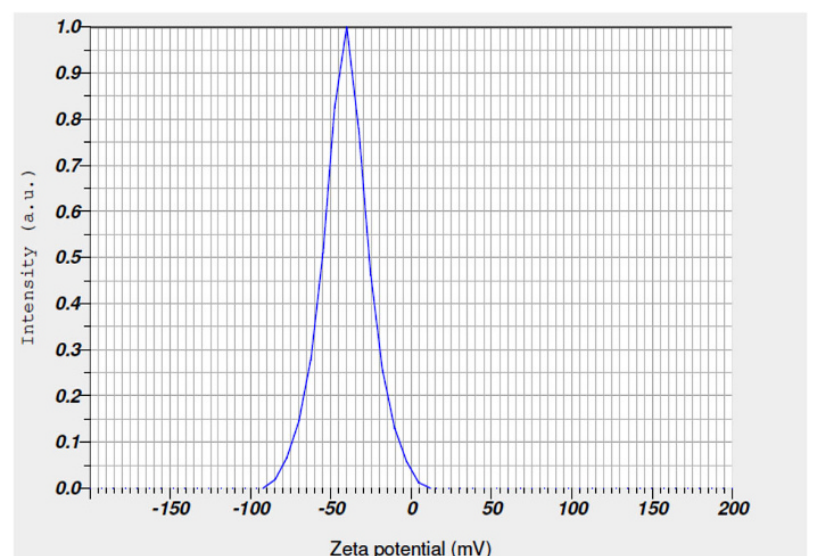

Calculation Results

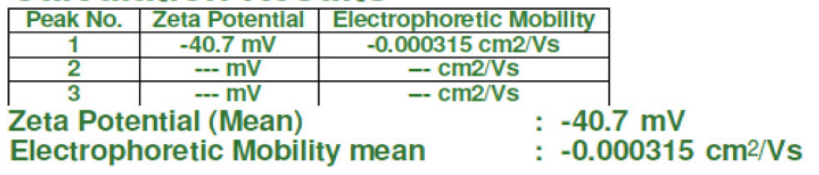

Fig. 2 Micrograph showing a negative zeta potential $(-40.7 \mathrm{mV})$ of the $\mathrm{n}-\mathrm{CaO}$ particles

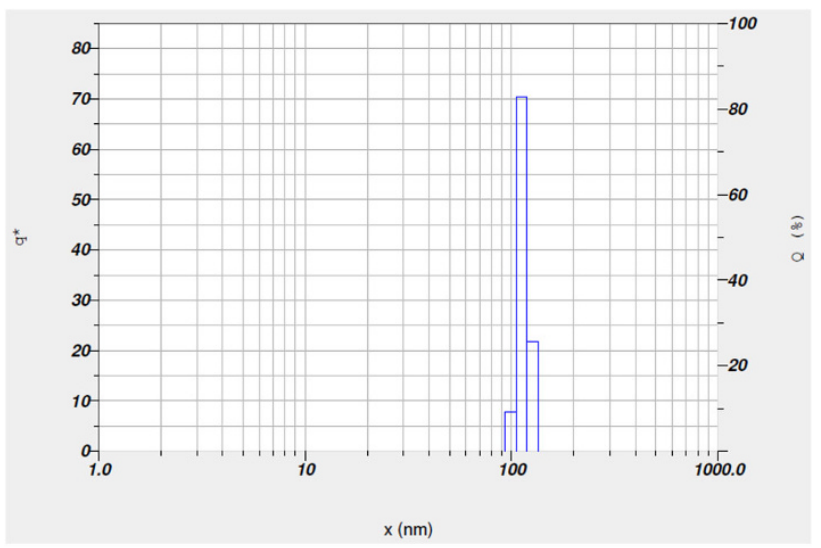

Calculation Results

\begin{tabular}{|c|c|c|c|c|}
\hline Peak No. & S.P.Area Ratlo & Mean & S. D. & Mode \\
\hline 1 & 1.00 & $113.9 \mathrm{~nm}$ & $7.4 \mathrm{~nm}$ & $113.1 \mathrm{~nm}$ \\
\hline 2 & $\cdots$ & $\cdots-\mathrm{nm}$ & $\cdots-\mathrm{nm}$ & $--\mathrm{nm}$ \\
\hline 3 & $\ldots$ & $\cdots-\mathrm{nm}$ & $\cdots-\mathrm{nm}$ & $--\mathrm{nm}$ \\
\hline Total & -- & $113.9 \mathrm{~nm}$ & $7.4 \mathrm{~nm}$ & $113.1 \mathrm{~nm}$ \\
\hline
\end{tabular}

Fig. 3 Histogram showing the particle size distribution and hydrodynamic diameter of the $\mathrm{n}-\mathrm{CaO}$ particles

and measured as size. The zeta potential, electrophoretic mobility and viscosity of the hydrosol were also measured using Nanopartica SZ-100 (HORIBA).

Statistical analysis

The experimental data were analyzed statistically by following standard procedure outlined by Panse and 
Sukhatme (1985). Significance was tested by comparing "F" value at five percent level of probability. Correlation studies were undertaken for different parameters of growth analysis, yield attributes and biochemical parameters according to the method proposed by Fisher and Yates (1963).

\section{Results and discussion}

The UV-Vis spectrograph showing the typical characteristic absorbance $(262 \mathrm{~nm})$ of $\mathrm{n}-\mathrm{CaO}$ (Fig. 1). The broadening of the absorbance spectra indicates that the $\mathrm{n}-\mathrm{CaO}$ particles are highly dispersed with uniform crystalline size. The high zeta potential value of $(-40.7 \mathrm{mV}) \mathrm{n}-\mathrm{CaO}$ also confirms that the particles are dispersed with strong electrostatic interaction forces (Fig. 2). The measured

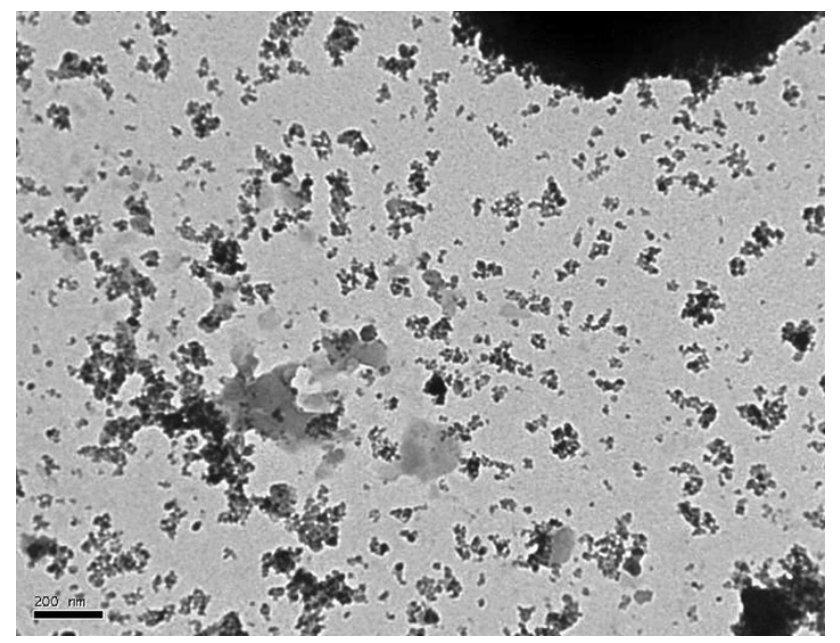

Fig. 4 Transmission electron microscopic view (200 nm-bar) of the calcium nanoparticles with mean size $30 \mathrm{~nm}$ hydrodynamic diameter using the dynamic light scattering technique was $113.1 \mathrm{~nm}$ (Fig. 3). The relatively higher size of the hydrosol may be due to the bulging effect. Spherical and agglomerated calcium oxide nanoparticles were observed in TEM micrograph (Fig. 4). The agglomeration of the particles is due to the absence of protecting ligands on the surface of the particles. In the micrograph, the measured average size of the particles is $30 \mathrm{~nm}$. Thus, the characterization of the $\mathrm{n}-\mathrm{CaO}$ revealed that the particles are highly stable with well-defined size and shape.

Since plants are unable to utilize calcium from old leaves, deficiency normally occurs first in the growing points and youngest leaves. Roots are usually affected before the tops, with both roots and tops exhibiting die back of the growing point. Where calcium deficiency is moderate to acute, root growth is markedly impaired and plants become susceptible to root-rot infection. Visual observations (Fig. 5) were made in development of deficiency and rectification in leaves and roots before and after spraying of different concentrations of nano-CaO, $0.1 \%$ $\mathrm{CaNO}_{3}$. Calcium content in different parts of the plant was analyzed and presented in Table 2 .

Roots

Before spraying, relatively higher calcium percent (63-72\%) was recorded in the roots of control plants compared to calcium-deficient plant roots. After spraying of $\mathrm{n}-\mathrm{CaO}$ and bulk calcium, significant differences were found between the treatments. After spraying of $n-\mathrm{CaO}$ at different concentrations (Fig. 6) and bulk calcium sources, calcium percent in the roots of deficient plants was significantly increased by $57.1-62.5 \%$ except in the treatment sprayed with bulk $\mathrm{CaO} 0.1 \%$.
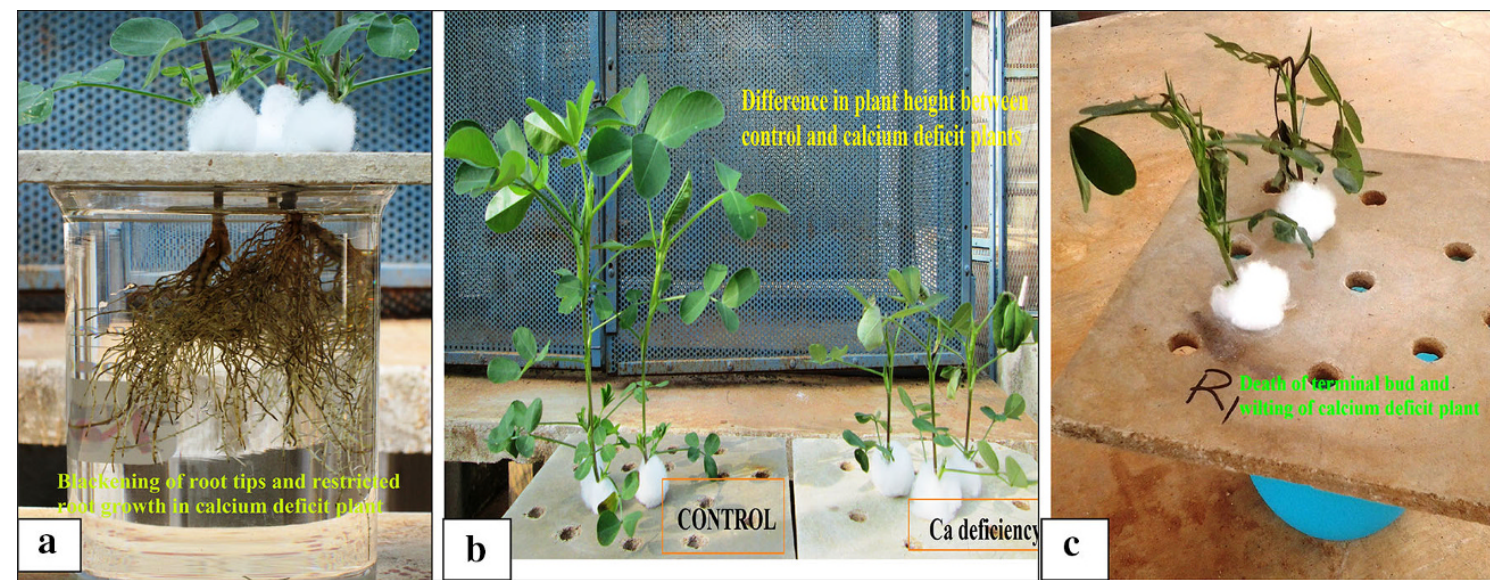

Fig. 5 Typical symptoms of calcium deficiency. a Blackening of the root tips with the restricted root growth in calcium-deficient plant. b Difference in plant height between control and calcium-deficient plants and c death of terminal bud and wilting of calcium-deficient plant 
Stems

Prior to imposing of the treatments, control plant stems recorded highest calcium percent $(80 \%)$ compared to calcium-deficient plant stems. After spraying of n-CaO at different concentrations and bulk calcium sources, calcium percent in the stems of deficient plants was significantly increased by $77.7-81.8 \%$, except in treatment bulk $\mathrm{CaO}$ $0.1 \%$. Among the $\mathrm{n}-\mathrm{CaO}$ treatments, $500 \mathrm{ppm}$ recorded

Table 2 Partitioning of calcium content (\%) in various parts of groundnut in response to foliar spray of nano- and bulk calcium under hydroponic conditions

\begin{tabular}{|c|c|c|c|c|c|c|}
\hline \multirow[t]{2}{*}{ Treatments } & \multicolumn{3}{|c|}{ Before spraying } & \multicolumn{3}{|c|}{ After spraying } \\
\hline & Root & Stem & Leaves & Root & Stem & Leaves \\
\hline Control & 0.011 & 0.010 & 0.010 & 0.011 & 0.007 & 0.005 \\
\hline $\mathrm{CaNO}_{3} 0.1 \%$ & 0.004 & 0.002 & 0.002 & 0.007 & 0.009 & 0.011 \\
\hline Bulk $\mathrm{CaO} 0.1 \%$ & 0.002 & 0.002 & 0.002 & 0.005 & 0.008 & 0.011 \\
\hline Nano-CaO 10 ppm & 0.003 & 0.002 & 0.002 & 0.007 & 0.009 & 0.011 \\
\hline Nano-CaO 50 ppm & 0.004 & 0.002 & 0.002 & 0.008 & 0.009 & 0.011 \\
\hline $\begin{array}{l}\text { Nano-CaO } \\
100 \text { ppm }\end{array}$ & 0.003 & 0.002 & 0.002 & 0.008 & 0.010 & 0.012 \\
\hline $\begin{array}{l}\text { Nano-CaO } \\
500 \mathrm{ppm}\end{array}$ & 0.003 & 0.002 & 0.002 & 0.008 & 0.011 & 0.013 \\
\hline \multirow{2}{*}{$\begin{array}{l}\text { Nano-CaO } \\
1,000 \mathrm{ppm}\end{array}$} & 0.003 & 0.002 & 0.002 & 0.008 & 0.010 & 0.012 \\
\hline & 0.004 & 0.0030 & 0.0030 & 0.0077 & 0.0091 & 0.0107 \\
\hline $\mathrm{SE} \pm \mathrm{m}$ & 0.00 & 0.00 & 0.00 & 0.00 & 0.00 & 0.00 \\
\hline CD $5 \%$ & 0.001 & 0.00 & 0.00 & 0.001 & 0.001 & 0.001 \\
\hline $\mathrm{CV}$ & 9.337 & 8.472 & 5.705 & 5.979 & 5.648 & 5.292 \\
\hline
\end{tabular}

highest calcium percent in stems which is $36.36 \%$ higher than control plant, $18.18 \%$ than $\mathrm{CaNO}_{3}$ and $27.27 \%$ than bulk $\mathrm{CaO}$. The concentrations of 100 and $1,000 \mathrm{ppm}$ of n-CaO showed on par with 500 ppm, but both concentrations showed $9 \%$ less calcium percent than $500 \mathrm{ppm} . \mathrm{Ca}^{2+}$ is transported in plant xylem vessel in chelate form and the speed of water flow is the key factor in $\mathrm{Ca}^{2+}$ transport via xylem in stem. There are both apoplastic and symplastic pathways of $\mathrm{Ca}^{2+}$ transport in fruit or leaf tissue too (Hong-Qiang and Yu-Ling 2005).

Leaves

Before spraying of treatments, control plant leaves recorded highest calcium percent ( $80 \%$ ) compared to calciumdeficient plant leaves. After spraying, among the $\mathrm{n}-\mathrm{CaO}$ treatments, plants treated with $500 \mathrm{ppm}$ concentration of $\mathrm{n}-\mathrm{CaO}$ recorded highest calcium percent in leaves which is numerically $61.53 \%$ higher than control plants, $15.38 \%$ than $\mathrm{CaNO}_{3}$ and $15.38 \%$ than bulk $\mathrm{CaO}$. After spraying of $\mathrm{n}-\mathrm{CaO}$ at different concentrations and bulk calcium sources, calcium percent in the leaves in deficient plants was increased by $81.8-84.6 \%$. However, foliar spray of bulk $\mathrm{CaO} 0.1 \%$ did not show any increment in the calcium content in leaves, root and stems which further establishes that no evidence of calcium transport through phloem. The $\mathrm{n}-\mathrm{CaO}$ concentrations of 100 and $1,000 \mathrm{ppm}$ were shown to be on par with $500 \mathrm{ppm}$, but both concentrations showed $7.61 \%$ less calcium percent than $500 \mathrm{ppm}$.

$\mathrm{Ca}^{2+}$ can enter cells passively through ion channels, but requires energy to be pumped out of the cytoplasm. The electrochemical potential for $\mathrm{Ca}^{2+}$ to enter the cytoplasm, across the plasma membrane was $-52 \mathrm{~kJ} / \mathrm{mol}$ (Spalding
Fig. 6 Correction of calcium deficiency in groundnut with the application of $500 \mathrm{ppm}$ of nanoscale calcium oxide nanoparticles $(30 \mathrm{~nm})$ in solution culture experiment: a before spraying. b After spraying of nano- $\mathrm{CaO}$ (500 ppm)
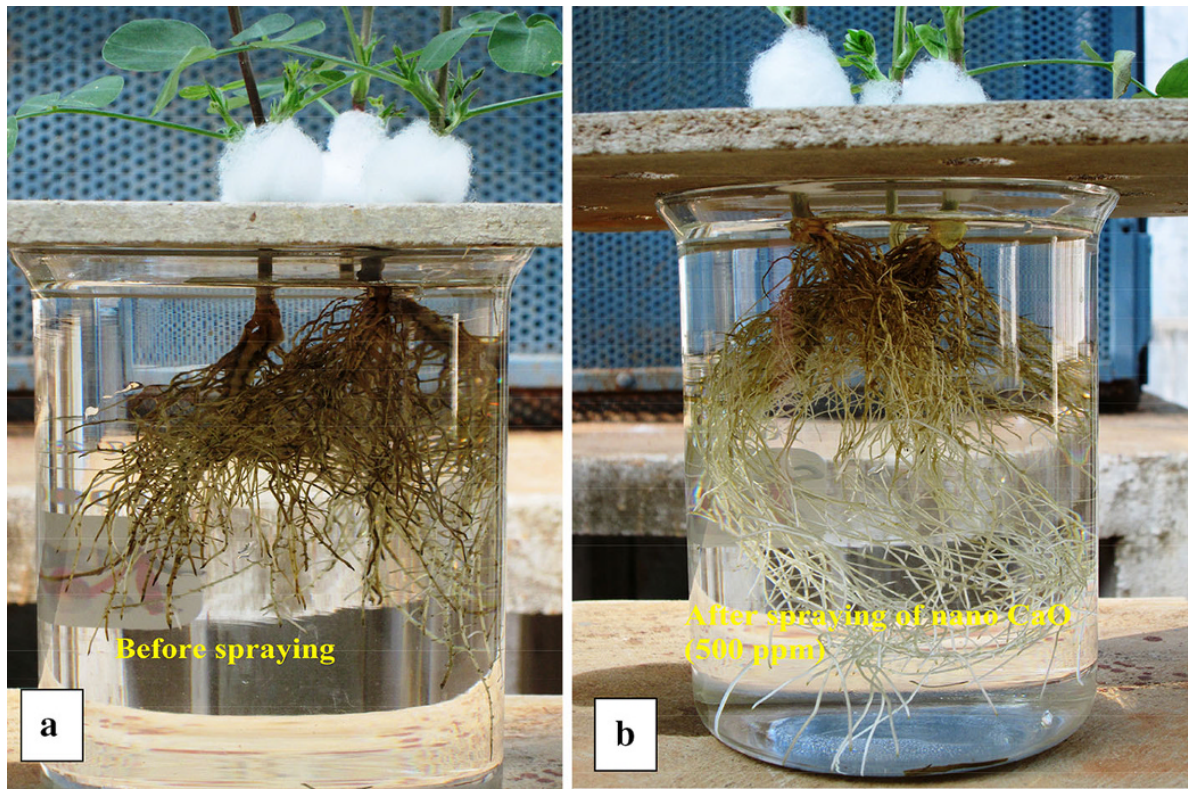
2011). Often, cytosolic $\mathrm{Ca}^{2+}$ levels fluctuate and they are in rapid control of membrane-localized $\mathrm{Ca}^{2+}$ pumps and channels located in plasmalemma, vacuoles and endoplasmic reticulum of plants (Stael et al. 2011; Ng and Mcainsh 2003; Yang and Poovaiah 2003). Therefore, it is anticipated that due to the small size, high surface area-tovolume ratio and continuum in flux, nanoscale calcium oxide particles could be transported with ease through ionic channels in the plant system and also we imagine that the relatively high electrochemical potential energy of the nanoscale materials also plays an important role in phloem transport of calcium oxide nanoparticles.

\section{Conclusion}

Phloem transport of nanoscale calcium oxide particles in groundnut using solution culture technique was confirmed for the first time which was an important breakthrough in agriculture and plant calcium nutrition. Calcium deficiency was well corrected by the application of nanoscale calcium oxide particles compared to their bulk counterparts (bulk $\mathrm{CaO}$ and $\mathrm{CaNO}_{3}$ ). Our experiments also once again verified and confirmed the restricted mobility of bulk calcium in phloem. Germination and growth of groundnut significantly increased with the foliar application of nanoscale calcium oxide particles (average particle size $30 \mathrm{~nm}$ ) and a dose of $500 \mathrm{ppm}$ is proved to be effective. Thus application of nanoscale materials in agriculture is promising and efficient translocation of the nutrients to the desired plant parts could be achieved, grains in particular, which is an utmost important outcome in human health perspective.

Open Access This article is distributed under the terms of the Creative Commons Attribution License which permits any use, distribution, and reproduction in any medium, provided the original author(s) and the source are credited.

\section{References}

Dhoke SK, Mahajan P, Rajashri K, Khanna A (2013) Effect of nanoparticles suspension on the growth of mung (Vigna radiata) seedlings by foliar spray method. Nanotechnol Dev 3(e1):1-5

Fisher, Yates (1963) Statistical tables for biology, agriculture and medical research. Oliver and Boyd, Edinburgh

Garica M, Forbe T, Gonzale E (2010) Potential applications of nanotechnology in the agro-food sector. Cienc Tecnol Aliment 30:573-581

Ghormade V, Deshpande MV, Paknikar KM (2011) Perspectives for nano-biotechnology enabled protection and nutrition of plants. Biotechnol Adv 29:792-803

Helper PK (2005) Calcium: a central regulator of plant growth and development. Plant cell 17:2142-2155
Johnson CM, Stout PR, Broyer TC, Carltont AB (1957) Comparative chlorine requirements of different plant species. Plant Soil 8:337-353

Lee WM, An YJ, Yoon H, Kweon HS (2008) Toxicity and bioavailability of copper nanoparticles to the terrestrial plants mungbean (Phaseolus radiatus) and wheat (Triticum aestivum): plant agar test for water-insoluble nanoparticles. Environ Toxicol Chem 27:1915-1921

Lin D, Xing B (2007) Phytotoxicity of nanoparticles: inhibition of seed germination and root growth. Environ Pollut 150:243-250

Lu CM, Zhang CY, Wen JQ, Wu GR, Tao MX (2002) Research of the effect of nanometer materials on germination and growth enhancement of Gylcine max and its mechanism. Soybean Sci 21:168-172

Ma Y, Kuang L, He X, Bai W, Ding Y, Zhang Z, Zhao Y, Chai Z (2010) Effects of rare earth oxide nanoparticles on root elongation of plants. Chemosphere 78:273-279

Meena S, Malarkodi M, Senthilvalavan P (2007) Secondary and micronutrients for groundnut. A review. Agric Reviews 28(4):1 (Abstract)

Monica RC, Lucia G, Chiara G, Roberto C (2011) The effects of nano- $\mathrm{TiO}_{2}$ on seed germination, development and mitosis of root tip cells of Vicia narbonensis L. and Zea mays L. J Nanopart Res 13:2443-2449

Nel A, Xia T, Madler L, Li N (2006) Toxic potential of materials at the nanolevel. Science 311:622-627

Ng CKY, Mcainsh MR (2003) Encoding specificity in plant calcium signaling: hot-spotting the ups and downs and waves. Ann Bot 92:477-485

Panse VG, Sukhatme PV (1985) Statistical methods for agricultural workers. ICAR, New Delhi

Prasad TNVKV, Sudhakar P, Sreenivasulu Y, Latha P, Munaswamy V, Raja Reddy K, Sreeprasad TS, Sajanlal PR, Pradeep T (2012) Effect of nano scale Zinc oxide particles on the germination, growth and yield of peanut. J Plant Nutr 35:905-927

Rashidi L, Khosravi-Darani K (2011) The applications of nanotechnology in food industry. Crit Rev Food Sci Nutr 51:723-730

Roco MC (2003) Broader societal issues of nanotechnology. J Nanopart Res 5:181-189

Sharon M, Choudary A, Kumar R (2010) Nanotechnology in agricultural diseases and food safety. J Phytol 2:83-92

Skelton BJ, Shear GM (1971) Calcium translocation in the peanut (Arachis hypogaea L.). Agronomy J 63:409-412

Spalding EP, Harper JF (2011) The ins and outs of cellular $\mathrm{Ca}^{2+}$ transport. Curr Opin Plant Biol 14:715-720

Srilatha B (2011) Nanotechnology in agriculture. J Nanomed Nanotechnol 2:123

Stael S, Wurzinger B, Mair A, Mehlmer N, Vothknecht UC, Teige M (2011) Plant organellar calcium signaling: an emerging field. J Exp Bot 63:1525-1542

Usten NH, Yokas AL, Saygili H (2006) Influence of potassium and calcium level on severity of tomato pith necrosis and yield of green house tomatoes. ISHS Acta Hortic 808:345-350

Webb AJ, Hansen AP (1989) Histological changes of the peanut (Arachis hypogaea) gynophore and fruit surface during development, and their potential significance for nutrient uptake. Ann Bot 64(3):351-357

Hong-Qiang Y, Yu-Ling J (2005) Uptake and transport of calcium in plants. J Plant Physiol Mol Biol 31(3):227-234

Yang T, Poovaiah BW (2003) Calcium/calmodulin-mediated signal network in plants. Trends Plant Sci 8:505-512 